\title{
Apócope do /r/ em graduados de uma cidade dos Campos Gerais, no Paraná: análise sociolinguística
}

\section{Apocope of the $/ \mathbf{r} /$ in undergraduate students from a city of the Campos Gerais, Paraná: a sociolinguistic analysis}

\author{
Vanessa Ribeiro* \\ Vanessa Veis Ribeiro** \\ Loremi Loregian-Penkal***
}

Resumo: A sociolinguística há muito tempo vem estudando a língua de acordo com as perspectivas de sua evolução cultural e de sua adaptação na sociedade em determinado tempo. Na pesquisa aqui proposta buscou-se analisar e descrever a apócope do /r/ no final das palavras na linguagem dos falantes nativos da cidade de Irati, PR. A amostra foi composta por oito falantes graduados divididos em dois grupos: um de faixa etária entre 20 e 35 anos, e o outro de faixa etária de 35 a 50 anos. Os falantes foram estratificados de acordo com a faixa etária e o sexo, e os focos de análise concentraram-se na tonicidade e no contexto fonológico seguinte. Com base na análise e interpretação dos dados, concluímos que a apócope do /r/ está diretamente relacionada com a idade, no sentido de que quanto menor é a idade do entrevistado maior é a ocorrência da apócope.

Palavras-chave: Sociolinguística. Apócope do /r/. Faixa etária. Sexo.

Abstract: Sociolinguistics has been studying language according to the perspectives of cultural evolution and its adaptation in society at specific times. This research proposal aimed at examining and describing the apocope of $/ \mathrm{r} /$ at the end of words in the language of inhabitants y of Irati-PR. The sample consisted of eight speakers divided into two groups, one group from ages between 20 to 35 years old, and the other aged 35 to 50 years. Speakers were stratified according to age and sex, and the analysis focused on the tone and the phonological context. After the analysis and interpretation of data, it was concluded that the apocope of the $/ r /$ is directly related to age, the younger the respondent the greater the occurrence of apocope.

Keywords: Sociolinguistics. Apocope of the /r/. Age. Sex.

A sociolinguística é a ciência que estuda a língua de acordo com sua interação com o meio social. Um dos principais nomes dessa linha teórica é William Labov que, em meados dos anos de 1960, obteve grandes descobertas,

\footnotetext{
"Fonoaudióloga; Universidade Estadual do Centro-Oeste. E-mail: <vanessa_ribeirinha@hotmail.com>

** Fonoaudióloga; Mestranda em Distúrbios da Comunicação Humana pela Universidade Federal de Santa Maria-UFSM. E-mail: <vanessaribeirooo@hotmail.com>

*** Doutorado em Lingüística pela Universidade Federal do Paraná, Brasil - Professora Associada A da Universidade Estadual do Centro Oeste, Brasil. E-mail: <Penkalloremi.loregian@gmail.com>
} 
as quais foram relevantes para entendermos o surgimento da linguagem. $\mathrm{O}$ autor desenvolveu grandes trabalhos a partir do estudo da sociolinguística. Como informa Tarallo:

Desde seu primeiro estudo em 1963, sobre o inglês falado na ilha de Martha's Vineyard, no Estado de Massachusetts (Estados Unidos), vários outros se seguiram: estudos sobre a estratificação social do inglês falado na cidade de Nova Iorque 1966; a língua do gueto: estudo sobre o inglês vernáculo dos adolescentes negros do Harlem, Nova Iorque, e estudos sociolinguísticos da Filadélfia, entre outros". (TARALLO, 2005, p.7)

De acordo ainda com Tarallo (2005), foi Labov quem voltou a insistir na relação entre língua e sociedade e na possibilidade de se sistematizar a variação existente e própria da língua falada. Observamos que Labov defende a teoria de que sem o social não se desenvolve a linguagem, e que essa constatação faz com que possamos abordar a implantação da variação da língua em diversos povos e diversas culturas. Neste sentido, Preti (2003) afirma que os estudos centrados na sociolinguística iniciaram nas décadas de 1950-60, nos Estados Unidos, e o interesse despertado deve-se à grande divulgação dos estudos de comunicação e à necessidade de melhor conhecimento da própria comunidade.

A nossa vida em sociedade é o que estabelece um mundo de signos e problemas os quais são resolvidos através de intercâmbio e a utilização da linguagem. Preti explica que:

Entre a sociedade e a língua não há uma relação de causalidade. Desde que nascemos, um mundo de signos linguísticos nos cerca, e suas inúmeras possibilidades comunicativas começam a tornar-se reais a partir do momento em que, pela imitação e associação, começamos a formular nossas mensagens. E toda a nossa vida em sociedade supõe um problema de intercâmbio e comunicação que se realiza fundamentalmente pela língua, os meios mais comuns de que dispomos para tal. (PRETI, 2003, p.13).

Diversas teorias antecederam a sociolinguística, dentre as quais demonstram maior destaque o gerativismo e o estruturalismo. O gerativismo constitui o estudo da língua mais voltado à aplicação de um tratamento matemático, preciso e explícito ao estudo das propriedades das linguagens naturais; em contrapartida temos o estruturalismo que obteve grande ênfase no século XX, 
e defendia um estudo mais voltado às questões da realidade social como um conjunto formal de relações.

Nesse contexto surge a sociolinguística, que obteve grande repercussão, abordando algo até então não proposto pelas teorias da época, que era o estudo da linguagem real, da fala, dentro de uma comunidade linguística, consequentemente, o objetivo da sociolinguística seria estudar padrões de comportamento linguísticos observáveis em uma comunidade de falantes. Isso ocorre a partir "do estudo formal e analítico de padrões em um sistema heterogêneo, reconhecendo a língua como uma realidade essencialmente social". (SILVA, 2009, p.27).

Já no Brasil, segundo Silva (2009), a sociolinguística apresenta algumas peculiaridades que a distinguem de outros países. Seja como for, a sociolinguística é uma ciência de vem crescendo fortemente e será o suporte teórico metodológico para a realização da nossa pesquisa.

São várias as temáticas abordadas pela sociolinguística, dentre elas a variação linguística, que abarca a diferenciação dos aspectos de linguagem que ocorrem em uma comunidade linguística em relação às outras. Ela pode ser determinada por fatores como tempo, espaço e as questões culturais exercidas pelas comunidades, entre outros.

"Para compreender Labov, temos de dar uma atenção maior ao conceito de variação e temos de percebê-la como requisito ou condição do próprio sistema linguístico" (MONTEIRO, 2000, p.57), ou seja, a variação é um aspecto de grande relevância do sistema linguístico.

De acordo ainda com Monteiro (2000), os modelos teóricos que fazem a abstração da variação entendem que ela é apenas um acidente e não uma característica essencial das línguas, sendo essa a base de diversas concepções.

"A variação é essencial à própria natureza da linguagem humana e, sendo assim, dado o tipo de atividade que é a comunicação linguística, seria a ausência de variação no sistema o que necessitaria ser explicado". (MONTEIRO, 2000, p. 57). Nesta perspectiva, a variação linguística se constitui no cerne da pesquisa sociolinguística, e é essa variação que virá ou não a constituir uma mudança linguística.

A nossa sociedade encontra-se em constante mudança, sendo promissora a substituição de algumas palavras ou aspectos linguísticos por outros. É comum hoje em dia, caso perguntarmos a um idoso o que ele acha 
da atualização da nossa língua, ele responder que mudou muito da sua época para o nosso cotidiano, que muitas palavras sofreram mudanças e que ele aderiu à utilização das mesmas com o passar do tempo. Portanto, "os fenômenos de mudança, decorrentes da variação, podem ser objeto de estudo e observação, contrariamente ao que pensavam outros linguistas". (MONTEIRO, 2000, p.109).

Não é fácil detectar por que ocorre uma mudança em determinada comunidade, mas, de acordo com Monteiro (2000), isso é uma questão de curiosidade que resulta em assuntos de estudos pela maioria dos linguistas. Para tentar explicar essa questão, várias hipóteses foram estabelecidas e, ainda segundo o mesmo autor, algumas hipóteses formuladas são mais fantasiosas e outras bastante sedutoras. Em geral, pode-se dizer que a falta de bases empíricas constitui um obstáculo para a aceitação dessas hipóteses, e é importante observar que cada qual focaliza diferentes aspectos buscando dados a respeito da origem da mudança linguística.

Assim, para explicar a mudança linguística, segundo Monteiro (2000), devem-se observar três aspectos de grande relevância, que são: a origem da mudança (em que a palavra é utilizada por um pequeno grupo de falantes); a propagação (em que um número considerado de falantes adere ao uso de uma nova palavra para substituir a antiga forma de uso); e a realização completa (em que se estabelece com regularidade a introdução da nova palavra na sociedade e todos da comunidade passam a utilizá-la). Seja qual for o critério de estudo para o entendimento da mudança linguística, é importante ainda que observemos que a mesma está presente em nossa sociedade e que estamos suscetíveis a ter mudanças em nosso vocabulário sempre de forma lenta, porém gradual.

As mudanças ocorrem sempre buscando a adequação linguística, que compreende a utilização concreta da língua levando em consideração o contexto de uso. "A existência de diversas linguagens é um fato que deve ser considerado em se tratando de comunicação ou adequação linguística. O importante no uso da linguagem é saber adequá-la conforme o ambiente, a situação e o público". (MARRECO et al, 2005, p.2).

Para haver adequação linguística, a situação e o momento vão ser dois parâmetros de grande relevância para o interlocutor. Por exemplo, com uma pessoa desconhecida, dificilmente alguém a cumprimenta dessa forma: “Oi querida, tudo bem com você? E aí, quais as novidades?", isto porque não se tem intimidade com a pessoa para perguntar as novidades, você nunca a viu antes, não sabe nem o que passou em sua vida anteriormente. 
"A adequação pode ser tomada como escolha, por parte do sujeito, de meios linguísticos apropriados a uma determinada finalidade" (COUTINHO, 2002, p.43), ou seja, os falantes precisam avaliar de que maneira irão tratar determinada pessoa, se vão fazer uso de uma linguagem mais culta, ou uma linguagem direta, dependendo da situação em que estão submetidos em uma comunidade linguística.

Para se fazer uma análise sociolinguística e averiguar a adequação linguística, é necessário levar em conta duas questões de grande interesse para a sociolinguística: a variável e a variante.

A variável é explicada como sendo "duas ou mais formas distintas de se transmitir um conteúdo informativo" (MONTEIRO, 2000, p.59), além do mais, a variável é constituída por variantes, ou seja, a variável depende diretamente da variante.

As variáveis são questões que envolvem dois ou mais objetos de estudo dentro de uma dimensão a ser analisada. A variável "sexo", por sua vez, mostra a diferenciação de maneira evidente sobre os pensamentos e os atos existentes no homem e na mulher. Essa diferença é retratada por Monteiro (2000) como sendo ponto pacífico: as mulheres e os homens não falam da mesma maneira. Considerando também as diferenças no ritmo e tom da voz, os indivíduos de diferentes sexos têm preferências por certas estruturas sintáticas, pelo emprego de determinados vocábulos ou fórmulas de cortesia, bem como pela omissão de outros em função das conotações que possam apresentar. Há inclusive certas crenças populares de que as mulheres falam muito mais que os homens ou que falam bem mais rápido.

As diferenciações no que se refere à fala da mulher e do homem são bem visíveis em nossa sociedade, principalmente nas questões de vocabulário, formações de frases e demais aspectos linguísticos.

Alguns estudiosos obtiveram diversas hipóteses tentando explicar o motivo da existência dessa diferenciação, aplicaram alguns estudos e experiências e levaram mais a fundo essa investigação a respeito da variação da fala de ambos os sexos. De acordo com Monteiro (2000), um nome de destaque foi Straka, que levantou a hipótese que essa variação poderia estar ocorrendo por conta das diferenciações fisiológicas existentes entre ambos no que se refere à capacidade pulmonar, segundo ele, as mulheres falam mais rapidamente porque, devido a uma capacidade pulmonar menor, ficam angustiadas e querem inserir o máximo possível de palavras entre duas respirações. 
Seja qual for a questão, o que devemos ter em mente é que há essa diferenciação não só na fala, mais em outras questões linguísticas envolvendo ambos os sexos.

Já com relação a variável "faixa etária", o objetivo é analisar as diferenças evidentes no que se refere à idade do falante. Como aborda Monteiro:

É fácil perceber que existem diferenças linguísticas devidas à idade do falante. As mais evidentes são, com certeza, as que se observam no período de aquisição da linguagem, quando, entre inúmeros fatos, a criança não consegue articular bem os fonemas (diz tatolim em vez de cachorrinho) ou generaliza a aplicação de um dado padrão morfossintático (sabi em vez de soube). Mas há também diferenças marcantes entre a linguagem de idosos e a dos adolescentes, bastando mencionar que aqueles mantêm certas construções léxicas ou sintáticas que podem até parecer estranhas. (MONTEIRO, 2000, p.76).

Essas alterações se devem a algumas mudanças no vocabulário pelo fato de estarmos em constantes adaptações em nossas vidas, e com relação a linguagem não é diferente.

É interessante levarmos em consideração essas duas variáveis para analisar os dados da pesquisa, pois envolvem todos os contextos e as diferenciações existentes em diferentes indivíduos dentro de uma comunidade, sendo de grande relevância para os estudos sociolinguísticos.

"Para Labov, a base da variação tem de estar na identidade lógica das variantes e também em seu paralelismo quanto ao significado sintático, semântico e pragmático". (MONTEIRO, 2000, p.62).

É bastante comum, de acordo com Monteiro (2000), que os falantes não aceitem facilmente o fato de que duas expressões diferentes signifiquem a mesma coisa, e em decorrência disso há uma forte tendência a conferir-lhes significados diferentes. Portanto, essa é uma questão que pode variar dentro de uma comunidade linguística, sendo que, por exemplo, determinada comunidade pode atribuir um valor diferente a alguma palavra em relação à outra comunidade linguística.

Em contrapartida "as variantes são sequências que têm o mesmo sentido e comportam os mesmos itens lexicais, mas seus processos combinatórios e hierarquias de categorias são diferentes" (MONTEIRO, 2000, p. 60), ou seja, é o item linguístico que é submetido constantemente a mudanças. As mesmas 
ainda podem ser classificadas como: variantes livres e combinatórias; variantes de prestígio; variantes estigmatizadas e variantes inovadoras e conservadoras.

As variáveis livres ou combinatórias estão presentes há bastante tempo, como observa Monteiro:

Durante bastante tempo, acreditou-se na existência de variações livres, desde que decorrentes da própria impossibilidade de se representar uma forma sempre exatamente da mesma maneira e de se chegar a uma identificação absoluta de realização entre todos os falantes de uma dada língua. Estabeleceu-se então uma separação entre dois tipos de variante: a livre, às vezes confundida com a estilística, e a combinatória ou contextual. (MONTEIRO, 2000, p.63).

Houve a necessidade da separação das duas justamente porque ambas analisam aspectos diferenciados dentro da sociolinguística. A diferenciação entre essas duas variantes ocorreu, segundo Monteiro, porque se duas unidades linguísticas figuram no mesmo ambiente e podem ser substituídas uma pela outra, então as duas unidades estão em variação livre e, se por outro lado, elas não se apresentam no mesmo ambiente, elas estão em distribuição complementar e são variantes combinatórias ou contextuais. Além disso, para a determinação dessas variáveis, levam-se em consideração as questões de fatores externos e níveis socioeconômicos.

A variante de prestígio se solidifica como uma expansão social, ou seja, um espelhamento da linguagem das camadas superiores pelas camadas mais baixas, sendo assim, uma variante adquire prestígio, de acordo com Monteiro (2000), se for associada a um falante ou grupo social de status considerado superior.

Por outro lado, a variante estigmatizada é muitas vezes adotada como fator de discriminação por muitos por pressupor a desvalorização social, ou seja, as variantes empregadas por falantes dos estratos mais baixos da população em grande parte são estigmatizadas. Essa variante pode ser observada, por exemplo, quando um falante é identificado como uma pessoa do interior, ou alguém da favela, apenas pela sua maneira de falar.

As variantes inovadoras e conservadoras têm relação direta com a mudança linguística e "há, então, uma espécie de conflito em que a forma mais antiga, denominada de conservadora, pode terminar sendo substituída pela mais recente ou inovadora”. (MONTEIRO 2000, p.65). Assim, podemos verificar 
que há vários tipos de variantes em uma comunidade linguística e todas elas são avaliadas, positiva ou negativamente, pelo viés social e não linguístico.

Devido a essa estigmatização da linguagem, pressupõe-se que os falantes busquem sempre a adequação linguística, ou seja, a norma padrão.

A norma padrão compreende aquilo que possibilita apenas uma colocação da língua de forma igualitária a todos os falantes, ou seja, um padrão linguístico a ser seguido por todos. Pensando nisso, Toniollo e Barufaldi (2009) afirmam que, para esclarecer o fenômeno linguístico da norma, é necessário levar em consideração as perspectivas linguísticas, pragmáticas e antropológicas.

Durante muitos anos, a língua vem sofrendo transformações, isso se deve em primeira instância por adaptações de questões culturais e sociais dos indivíduos.

A transformação de uma língua opera-se pelo constante contato com outras línguas ou mesmo com variantes regionais e sociais. Esse processo é inevitável, porque nenhum povo vive isolado. Porém, essa transformação afasta o falante do uso da língua padrão. Assim a distância entre a linguagem coloquial e a norma padrão torna-se cada vez maior. (MARRECO et al, 2005, p.1).

Justamente o convívio entre diversos povos e as trocas de informações entre os mesmos são os principais causadores de ajustes à substituição da língua padrão, com o principal objetivo de facilitar a comunicação e se adaptar a novas modalidades linguísticas, porém é importante que os linguistas tenham a norma culta presente dentro do seu domínio, pois "com o domínio da norma culta o indivíduo sente-se livre para se comunicar e usar tal variedade quando necessário”. (MARRECO et al, 2005, p.2).

É evidente que a ausência de um vocabulário mais culto trará certo constrangimento a um indivíduo quando exposto a situações formais, pois é difícil comunicar-se em diversas situações quando o indivíduo tem conhecimento de apenas uma variedade linguística. Então a maneira mais fácil seria o indivíduo ter acesso a mais variedades linguísticas. Como abordado por Sarcconi (1995, apud Marreco et al, 2005, p.3): “[...] um indivíduo só pode dizer-se livre no âmbito de comunicação linguística, quando conhece várias modalidades da língua e escolhe aquela que melhor convém ao momento do discurso". Portanto, o indivíduo estando em contato com variedades linguísticas vai apresentar diversas probabilidades de comunicação, sem que 
haja constrangimento do mesmo quando exposto aos mais diversos meios de linguagem, tanto no que se refere à linguagem escrita como à linguagem oral.

De acordo com Bagno (1999), a estigmatização das variáveis linguísticas leva ao preconceito linguístico, que nada mais é que o preconceito que se dá às variedades linguísticas.

Percebe-se, porém, que não há o predomínio de uma única língua, ou forma de linguagem proposta pela sociedade, há predomínio de várias formas de variações dentro de uma língua, o que acaba acarretando preconceito por boa parte da população em relação a uma pessoa, por exemplo, com nível de estudo menor que os demais.

Sendo assim, podemos analisar que essa questão do preconceito linguístico deve ser amenizada pela sociedade à medida que os anos passem, porém, ainda não se sabe ao certo até que ponto vai a avaliação negativa da sociedade em relação às variáveis linguísticas expostas pelas diversas regiões e culturas do nosso país e do mundo todo.

Nosso foco de análise será baseado em alterações fonéticas que ocorrem em palavras dentro de uma língua em um decorrer de tempo, ou seja, os metaplasmos. E "entende-se por metaplasmos as modificações fonéticas ocorridas com a sua evolução. Essas mudanças são facilmente vistas na língua portuguesa, cada geração altera as palavras inconscientemente para atender às necessidades de sua época". (GOMES et al, 2007, p.3).

De acordo com Botelho e Leite (2005), ao se analisar os metaplasmos verifica-se que eles podem ocorrer de quatro maneiras: por aumento, por supressão, por transposição e por transformação; e, sendo assim, cada caso constitui um objeto de estudo.

O metaplasmo por aumento ocorre quando inserimos um fonema no vocábulo, aumentando assim a sua forma fonética. Os metaplasmos por transição podem ocorrer "por deslocamento de posição de fonemas em um vocábulo ou por transposição do acento tônico da palavra". (BOTELHO \& LEITE, 2005, p.5). Por sua vez, os metaplasmos por transformação podem ocorrer "quando um fonema de um vocábulo se transforma, passando a ser outro fonema distinto em lugar do primeiro". (BOTELHO \& LEITE, 2005, p.6). Já os metaplasmos por supressão "ocorrem quando suprimimos um fonema de um vocábulo. Veremos nesse grupo os fenômenos da aférese, da apócope, da síncope e da haplologia". (BOTELHO \& LEITE, 2005, p.4). 
Será dada maior ênfase no estudo da apócope, sendo este o foco da nossa pesquisa. De acordo com Botelho e Leite (2005), a apócope refere-se ao nome dado ao fenômeno pelo qual se suprime um fonema no final do vocábulo, como por exemplo: bobagem $>$ bobage; quer $>$ qué; saber $>$ sabê; passar $>$ passá; parênteses $>$ parêntese; furúnculo $>$ furunco; lâmpada $>$ lampa; rapaz $>$ rapá, e pôr $>$ pô.

Para o aprofundamento no estudo da apócope, utilizaremos os princípios da pesquisa sociolinguística. $\mathrm{O}$ foco de análise da pesquisa sociolinguística é o vernáculo, que nada mais é que a linguagem utilizada pelo indivíduo no dia a dia. $\mathrm{O}$ vernáculo é encontrado nas expressões de fala informal, nos diálogos com amigos, em família. Tarallo (2005) afirma que a língua falada é o veículo linguístico de comunicação usado pelas pessoas em situações naturais de interação social, do tipo comunicação face a face.

Para se conseguir efetuar uma pesquisa sociolinguística é preciso ter uma quantidade expressiva de dados, visto que a pesquisa é de natureza quantitativa, de modo que possa facilitar a interpretação do corpus, levando-se em conta a variável estudada e os objetivos centrais da questão.

Para tanto, é notável que a variável fonológica é mais encontrada na fala do que a variável sintática, sendo que para se chegar com mais precisão a essa segunda análise o pesquisador precisa de uma quantidade maior de material coletado.

A melhor maneira de coletar dados sociolinguísticos ocorre quando o pesquisador é conhecedor da comunidade em questão, porque, segundo Tarallo (2005), é necessário que o pesquisador sociolinguista participe diretamente da interação. Ainda de acordo com esse autor, a entrevista deve ser feita de maneira que o pesquisador interfira o menos possível, sendo de extrema importância que o pesquisador não aponte a língua como o objeto de estudo a ser abordado, pois com isso as pessoas vão prestar atenção à sua linguagem, corrigindo-se, e, desta forma, não proporcionando dados fidedignos.

A utilização de roteiros facilita a coleta de dados em uma pesquisa, pois a maneira como se coleta os dados é crucial à sociolinguística e à confiabilidade da pesquisa a ser desenvolvida.

A narrativa vem sendo um meio de se obter os dados. Nesse sentido Tarallo (2005) afirma que ao narrar suas experiências pessoais mais envolventes, o informante desvencilha-se das preocupações com a forma. Assim, o informante acaba deixando de lado a maneira como ele fala para prestar atenção 
no que ele fala, ou seja, no assunto que está sendo narrado. Acredita-se que estudar os indivíduos que possuam ensino superior completo é interessante, visto que os graduados tem um nível de escolaridade maior, que possa ser um fator facilitador para a não ocorrência da apócope final do /r/.

O presente estudo tem por objetivo analisar a linguagem falada de oito informantes, nativos de Irati, graduados, analisando a interferência de variáveis extralinguísticas na apócope do " $\mathrm{r}$ " em uma cidade da região dos Campos Gerais, no estado do Paraná.

\section{Materiais e métodos}

Para elaboração deste estudo foram realizadas entrevistas com 8 indivíduos da cidade de Irati, PR, estratificados de acordo com sexo, faixa etária e escolaridade. A faixa etária dos indivíduos variou de 20 a 50 anos, sendo 4 homens e 4 mulheres, todos possuindo graduação completa.

Adotou-se como critérios de inclusão na pesquisa ser nativo da cidade de Irati, PR, e ter formação acadêmica de nível superior ou estar cursando o ensino de $3^{\circ}$ grau. Todas as entrevistas tiveram como base a metodologia de coleta de dados da sociolinguística variacionista (TARALLO, 1999).

De acordo com a metodologia da sociolinguística variacionista, os participantes foram selecionados aleatoriamente na população da cidade de Irati. Para participar na pesquisa foi necessário ter o perfil condizente com os critérios de estratificações estabelecidos. Os selecionados assinaram o Termo de Consentimento Livre e Esclarecido (TCLE) e preencheram uma ficha com dados de identificação geral. Com o preenchimento dos dados pessoais realizado, foi feita a coleta de dados linguísticos, sendo que o pesquisador busca na hora da entrevista o vernáculo, que é a fala mais espontânea dos indivíduos.

Foi utilizado um aparelho MP4 para a gravação dos dados, tomando-se o máximo de cuidado com o paradoxo do observador, ou seja, o falante disfarçar ou modificar sua fala pela presença do gravador. Isso foi possível por meio da realização de perguntas do cotidiano do indivíduo, onde o mesmo se esquecia da presença do MP4 ao narrar histórias de acontecimentos pessoais.

A entrevista foi de forma semi-dirigida ou semi-aberta, em que se utilizou um protocolo com perguntas pré-formuladas, porém, sem necessidade de dar seguimento nas perguntas, lembrando que o objetivo era fazer com que o falante se envolvesse em sua fala, obtendo-se assim o vernáculo. 
De posso corpus, foram efetuadas inicialmente as transcrições dos dados dos falantes universitários, e, em seguida, o levantamento dos dados dos falantes de nível fundamental e médio, cujas transições já estavam disponíveis. Na sequência, foram amrcadas as sentenção em que havia presença e ausência do /r/ final, e desses procedemos, então, à análise e comparação dos dados das diferentes faixas etárias. O foco de análise concentrou-se no comportamento das variáveis: faixa etária e sexo.

\section{Resultados e discussão}

$\mathrm{Na}$ cidade de Irati, buscamos retratar se as variáveis faixa etária e sexo são relevantes no que se refere à queda do /r/ no contexto universitário, desta forma houve a seleção de uma amostra populacional.

O estudo nos mostra que está ocorrendo, sim, uma mudança na sociedade onde vivemos como enfoque maior à variação linguística. Como observa Monteiro (2000), a variação linguística é essencial para a adaptação do ser humano ao novo sistema linguístico que é implantado pela sociedade em um decorrer de tempo. Outra questão que também é evidente em nosso estudo, corroborando os pressupostos de Monteiro (2000), é o fato de que os homens e as mulheres não falam da mesma forma, cada qual desenvolvendo as suas particularidades, além das diferenciações que envolvem o ritmo e o tom da voz, cada um destes apresenta preferências por determinadas estruturas sintáticas e pelo emprego de determinados vocábulos.

Para melhor compreensão do assunto em questão, na Tabela 1 os falantes compõem uma amostra de faixa etária de 20 a 50 anos, sendo apenas levado em consideração o fator sexo, para análise da queda do /r/ final na fala espontânea. Essa tabela apresenta o apócope do /r/ final versus o número total de palavras finalizadas em /r/, sendo obtido o percentual da relação. Os principais resultados obtidos podem ser conferidos na tabela seguir:

Tabela 1- Ausência de /r/ de acordo com o sexo do informante

\begin{tabular}{c|c|c}
\hline Fatores & Sem apócope / Total & \% \\
\hline Feminino & $537 / 762$ & 70 \\
\hline Masculino & $509 / 975$ & 52 \\
\hline Total & $1046 / 1737$ & 60 \\
\hline
\end{tabular}


De acordo com os resultados contidos na Tabela 1, podemos observar que as mulheres apresentam um valor mais alto de queda do $/ \mathrm{r} / \mathrm{com}$ um percentual de $70 \%$, em contrapartida os homens obtiveram um percentual de $52 \%$, havendo deste modo uma diferenciação de $18 \%$. Diante desta questão, podemos considerar que o fenômeno em estudo não seja estigmatizado na sociedade analisada. Isto porque, segundo os estudos variacionistas, a tendência das mulheres é liderar fenômenos que possuem prestígio na comunidade de falantes, o que não acontece na sociedade estudada.

A Tabela 2 nos mostra a análise obtida a partir da queda do /r/ final no contexto fonológico seguinte versus o número total da ocorrência de palavras com terminação em /r/ do mesmo contexto fonológico, sendo distribuídos os indivíduos em dois grupos, o primeiro abordando as faixas etárias de 20 a 35 anos e o segundo as faixas etárias de 35 a 50 anos, pretendendo, deste modo, analisar se há diferenças evidentes no que se refere à idade do falante relacionado à apócope do $/ \mathrm{r} /$.

Tabela 2 - Apagamento do /r/ de acordo com a idade e com o contexto fonológico seguinte

\begin{tabular}{c|c|c|c}
\hline Idade & Vogal/Total/\% & Consoante/Total/\% & Pausa/ Total/\% \\
\hline 20 a 35 anos & $295 / 448 / 66 \%$ & $339 / 598 / 56 \%$ & $19 / 37 / 51 \%$ \\
\hline 35 a 50 anos & $156 / 259 / 60 \%$ & $212 / 368 / 57 \%$ & $23 / 27 / 85 \%$ \\
\hline Total & $451 / 707 / 64 \%$ & $551 / 966 / 57 \%$ & $42 / 64 / 65 \%$ \\
\hline
\end{tabular}

A Tabela 2 nos mostra que quando o contexto seguinte é uma vogal há uma tendência de favorecimento da queda do /r/ nas duas faixas etárias, com uma diferença percentual de apenas 6\% entre elas. Quando o contexto seguinte é consoante, vemos que há uma diferença mínima de $1 \%$ entre as duas faixas etárias e mesmo assim com um leve favorecimento da queda do /r/. Já em relação à pausa, temos a maior diferença entre as duas faixas etárias: os mais jovens, com $51 \%$, favorecendo menos a queda do $/ \mathrm{r} /$, e os falantes de 35 a 50 anos aparecem com um percentual elevado, $85 \%$ de queda do $/ \mathrm{r} /$. Esse resultado difere de outros estudos sobre o mesmo fenômeno, pois o esperado seria que os falantes mantivessem mais o $/ \mathrm{r} /$ antes de pausa por ser um contexto de fala mais perceptível para o interlocutor. Os achados vão ao encontro da afirmação de Monteiro (2000), no sentido que, de certo modo, é fácil perceber que existem diferenças linguísticas entre falantes relacionadas com a questão 
de idade, e que há diferenças marcantes entre a linguagem do adolescente e do idoso, sendo estas visíveis pela sociedade.

Na Tabela 3 podemos observar dados relacionados à queda do $/ \mathrm{r} / \mathrm{final}$ no que se refere à tonicidade das palavras versus o número total da ocorrência de palavras com terminação em /r/ do mesmo contexto de tonicidade. Sendo distribuídos os indivíduos em dois grupos, o primeiro abordando as faixas etárias de 20 a 35 anos e o segundo as faixas etárias de 35 a 50 anos, pretendendo obter análises se o fator faixa etária exerce função sobre a queda do /r/ final durante a fala espontânea.

Tabela 3 - Análise da tonicidade das palavras que retratam ausência do /r/ final de acordo com a faixa etária

\begin{tabular}{c|c|c|c}
\hline Idade & Oxítonas & Paroxítonas & Proparoxítonas \\
\hline 20 a 35 anos & $653 / 653=100 \%$ & $0 / 0=0 \%$ & $0 / 0=0 \%$ \\
\hline 35 a 50 anos & $391 / 391=100 \%$ & $0 / 0=0 \%$ & $0 / 0=0 \%$ \\
\hline Total & $1046 / 1046=100 \%$ & $0 / 0=0 \%$ & $0 / 0=0 \%$ \\
\hline
\end{tabular}

Analisando a tabela, podemos observar que os dados levantados são de grande relevância para nosso estudo, pois o que abordamos é que tanto o grupo de 20 a 35 anos como o grupo de 35 a 50 anos promovem o apagamento do /r/ final em (100\%) das palavras com tonicidade na última sílaba, ou seja, sendo estas caracterizadas como oxítonas.

$\mathrm{Na}$ Tabela 4 abordamos os dados relacionados a queda do /r/ final no que se refere ao fator da gramática e suas divisões versus o número total da ocorrência de palavras com terminação em /r/ do mesmo contexto de gramatização. Sendo distribuídos os indivíduos em dois grupos, o primeiro abordando as faixas etárias de 20 a 35 anos e o segundo as faixas etárias de 35 a 50 anos, pretendendo obter análises se o fator faixa etária exerce função sobre a queda do /r/ final durante a fala espontânea.

Tabela 4 - Apagamento do /r/ final de acordo com a classe gramatical.

\begin{tabular}{c|c|c|c|c}
\hline Idade & Verbos & Preposição & Adjetivo & Substantivo \\
\hline 20 a 35 anos & $653 / 1046=62,62 \%$ & $0 / 0=0 \%$ & $0 / 0=0 \%$ & $0 / 0=0 \%$ \\
\hline 35 a 50 anos & $391 / 1046=37,38 \%$ & $0 / 0=0 \%$ & $0 / 0=0 \%$ & $0 / 0=0 \%$ \\
\hline Total & $1046 / 1046=100 \%$ & $0 \%$ & $0 \%$ & $0 \%$ \\
\hline
\end{tabular}


$\mathrm{Na}$ Tabela 4 observamos que tanto o grupo de 20 a 35 anos como o grupo de 35 a 50 anos também promovem o apagamento do /r/ final em 100\% das palavras que fazem parte da classe gramatical "verbos". Observa-se que o apagamento do /r/ final é feito em igual valor pelos indivíduos da faixa etária 20 à 35 anos, e da faixa etária 35 a 50 anos, porém, ele ocorreu mais vezes na fala de pessoas com faixa etária de 20 a 35 anos.

Compreendemos neste caso e no anterior que a variável faixa etária não exerceu influência sobre estas duas "investigações", discordando, portanto da maioria das pesquisas variacionistas que afirmam ser presente a diferenciação nas faixas etárias no que se refere ao fator de linguagem.

\section{Considerações finais}

Com base na análise dos dados podemos concluir que, em nosso estudo, foi visível esta diferenciação em relação ao fator sexo: as mulheres apresentam maior tendência ao apagamento do /r/ final durante a fala espontânea.

No que se refere à análise por faixa etária, percebemos que este fator exerce grande influência, pois, como abordado em nosso estudo, anteriormente observamos que os falantes de 35 a 50 anos apresentam percentuais mais elevados de apagamento do /r/, principalmente no contexto de pausa. Esta questão é de suma importância sendo que este estudo difere dos demais apresentados, já que o contexto pausa é uma questão mais perceptível ao interlocutor.

Em se tratando da análise por classe gramatical obtivemos que o contexto que mais propiciou a queda do /r/ foi a classe gramatical dos "verbos", o mesmo se aplica à condição de análise da tonicidade das palavras, na qual se registrou que as oxítonas preponderaram em cem por cento dos casos.

\section{Referências}

BAGNO, M. Preconceito linguístico: o que é, como se faz. São Paulo: Loyola, 1999.

BAGNO, M.; RANGEL E. O. Tarefas da educação linguística no Brasil. Revista Brasileira de Linguística Aplicada, v.5, n.1, 2005, p. 63-81.

BARAFFADI, V. B.; TONIOLI S. Sociolinguística: uso e norma da fala urbana. In: Acervo de Artigos de Pós-graduação do Centro Universitário FIEO. Osasco-SP. Disponível em: $<$ http://www.fieo.br/edifieo/index.php/posgraduacao/article/view File/148/241 > . Acessado em 20/02/10. 
BOTELHO, J. M.; LEITE, I. L. Metaplasmos contemporâneos: um estudo acerca das atuais transformações fonéticas do português. In: Congresso de Letras da Universidade do Estado do Rio de Janeiro, 2., 2010, São Gonçalo. Anais... São Gonçalo: Universidade do Estado do Rio de Janeiro, 2005.

COUTINHO, M. A. Perspectivas linguísticas sobre a noção de estilo. In: Actas do Encontro Comemorativo dos 25 anos do CLUP. Porto: CLUP, 2002, v.2, p. $41-54$

GOMES, M. J. T. \& GOMES, S. E. S. Metaplasmos por aumento na fala de paraguaios residentes no Matogrosso do Sul. In: CELLMS, 5., 2010, Jardim. Anais... Jardim-MS: Universidade do Estado do Mato Grosso do Sul, 2010.

MARRECO, R. T. M.; MATTOS, E. S. O coloquialismo e a norma padrão na fala cotidiana de futuros profissionais. Revista eletrônica de Divulgação Científica em Língua Portuguesa, Linguística e Literatura. n. 10, p. 01-17, $1^{\circ}$ sem. 2009. Disponível em: <http://www. letramagna.com/coloquialismopadrao.pdf>. Acesso em: 15/02/10.

MONTEIRO, J. L. Para compreender Labov. Rio de Janeiro: Vozes, 2000.

PRETI, D. Sociolinguística, os níveis de fala: um estudo sociolinguístico do diálogo na literatura brasileira. São Paulo: Editora da Universidade de São Paulo, 2003.

SILVA, M, L, da. A linguística e a sociolinguística numa perspectiva brasileira. Revista Filosofia Capital. Brasília-DF: v.4, ed.8, 2009.

TARALLO, F. A pesquisa sociolinguística. São Paulo: Ática, 1998.

Recebido para publicação em 03 de dezembro de 2010. Aceito para publicação em 09 de abril de 2012. 